\title{
Gereja Karismatik dan Inkulturasi Musik di Dalam Sistem Ibadahnya
}

\author{
M. Hari Sasongko ${ }^{1}$
}

\begin{abstract}
The charismatic movement is an embryo of the birth of charismatic church in the world. The movement was began before the World War where the situation was marked by the economical decadence, particularly in the United States of America that caused uneasiness in several live of young community. The church model based on the power of Holly Spirit in the comprehension of Christian traditional faith. It is differenced from another church that grows in Europe. The church has been developing and finally, it is taking root on Western culture tradition, and then it appeared gospel music tradition. Unfortunately the members of this religious community are disposed another musical tradition that lives around them whereas they are something important to the success of progress of cultural dialog, so the charismatic chruch seem exclusive. By mean of historical studies, the writer try to critise on the prospect dialog between charismatic church and local tradition. The dialog will open the posibility of cultural spirit to furnish, support, and appreciate one to another.
\end{abstract}

Keywords: charismatic, local music tradition, dialog, religious.

\begin{abstract}
Abstrak
Gerakan karismatik adalah cikal bakal kelahiran gereja karismatik di dunia. Gerakan ini dimulai sebelum Perang Dunia di mana situasi ditandai oleh dekadensi ekonomi, khususnya di Amerika Serikat yang menyebabkan di beberapa komunitas muda. Model gereja berdasarkan kekuatan Roh Kudus yang secara tradisional tidak dapat dipisahkan dari iman Kristen. Ini berbeda dari gereja lain yang tumbuh di Eropa. Gereja telah berkembang dan akhirnya, ia mengakar pada tradisi budaya Barat, dan kemudian muncul tradisi musik gospel. Sayangnya para anggota komunitas religius ini mulai mengesampingkan tradisi musik yang hidup di sekitar mereka padahal music-musik tersebut merupakan sesuatu yang penting bagi keberhasilan kemajuan dialog budaya. Di sinilah gereja kharisma karismatik menjadi tampak eksklusif. Lewat kajian historis, penulis mencoba mengulas prospek dialog antara gereja karismatik dengan tradisi local tempat gereja itu tinggal. Dialog ini akan membuka semangat untuk saling menghargai, mendukung, dan mengembangkan.
\end{abstract}

Kata kunci: karismatik, tradisi musik lokal, dialog, agama.

\footnotetext{
${ }^{1}$ Doktor dari Program Pascasarjana S-3 Bidang Humaniora UGM Yogyakarta.
} 


\section{Pendahuluan}

Agama Kristen adalah agama yang memiliki banyak denominasi. Akan tetapi dari sekian banyak denominasi, ciri khasnya dapat dikelompokkan menjadi tiga bagian, yakni liturgika, koinonia, dan kharismatik. Pembahasan di bawah ini lebih memfokuskan diri pada ciri khas gereja yang terakhir karena memiliki latar belakang yang unik, terutama dalam kaitannya dengan paradigma gereja ini terhadap tradisi musikal dan bentuk-bentuk sikap penerimaan mereka terhadap gaya-gaya/idiom-idiom musik yang bersifat tradisional atau lokal. Melalui studi historis sikap penerimaan tersebut relatif menjadi jelas.

\section{Gerakan Kharismatik}

Kharismatik adalah aliran agama Kristen yang menonjolkan atau bercirikan karunia rohani atau gerakan roh (Karl Rahner, 1975: 184-185). Kata "Kharismatik" berasal dari bahasa Yunani; $\chi \dot{\alpha} \rho \imath \sigma \mu \alpha=$ Kharisma (tunggal) atau Kharismata (jamak) yang artinya karunia roh (Wilfred J. Samuel, 2006).

Pandangan ini berdasar pada Alkitab Perjanjian Baru yang secara spesifik terdapat dalam Surat Roma 1:11, 5:15-16, 6:23, 11:29, 12:6, Surat I Korintus 1:7, 7:7, 12:4, 9, 28, 30-31, Surat II Korintus 1:11, Surat I Timotius 4:14, Surat I Timotius 1:6 dan Surat I Petrus 4:10 (L. Sugiri S., 2006: 254-274). Hal ini dipercaya sebagai pekerjaan Yesus Kristus dalam Roh Kudus. $^{2}$ Aliran ini sebenarnya sudah ada sejak zaman reformasi yang dikenal dengan Anabaptisdi Eropa, yakni gerakan yang lahir saat reformasi Lutheran di abad ke-16. ${ }^{3}$ Penganutnya bahkan mengaku sudah ada sejak gereja mula-mula abad ke-2, yaitu yang dikenal dengan montanisme ${ }^{4}$, namun baru muncul sebagai gereja di abad dua puluhan (John Meyendorff, 1982: 198-199).

Kemunculannya banyak mendapatkan sambutan di berbagai negara namun juga terkadang menimbulkan reaksi gereja-gereja resmi seperti Katolik, Presbiterian, Kongregasional, Anglikan dan sebagainya (Matthew Heato, 2008: 221). Gerakan ini ada

\footnotetext{
${ }^{2}$ Roh Kudus atau Roh Allah atau Roh Anak Allah (Gal 4:6) ialah Roh pelaksana kehendak Allah di bumi. Ia sebagai Penghibur (Penolong) yang melanjutkan dan menerapkan karya Keselamatan Yesus. Dialah dinamik pekabaran Injil. Ia memberi kesaksian Allah dalam hati orang-orang percaya bahwa mereka anak-anak Allah (Roma 8:15-16).

${ }^{3}$ Saat itu kaum Anabaptis sudah menyadari dan menentang ajaran teologi kekristenan Katolik Roma klasik termasuk juga menentang ajaran Lutheran. Secara teologis mereka sangat menekankan atas Roh Kudus, pengharapan kedatangan segera Yesus Kristus yang kedua kali, pasifisme dan taat akan aturan etika yang ketat.

${ }^{4}$ Montanisme merupakan gerakan profetis yang dipelopori oleh Montanus, seorang mantan imam dari kota Sybele di Phrygia, yang menekankan pengajarannya kepada nubuatan-nubuatan yang disampaikan dalam keadaan ekstasis dan juga pengajaran Allah berkomunikasi langsung dengan wahyu melalui Roh Kudus.
} 
yang menjadi gereja, namun juga ada yang tetap menjadi gerakan atau sekte, atau juga disebut Gerakan Pentakostal Baru, atau Gerakan Zaman Baru, atau Gerakan Gelombang ke Tiga jika dilihat dari ajaran teologinya (J. L. Ch. Albineno, 1976: 17).

Kegerakan Kharismatik yang merupakan kelanjutan dari kegerakan Pentakosta ${ }^{5}$ memiliki banyak kemiripan antara lain keduanya mengakui kuasa Roh Kudus dan Kesembuhan Ilahi, dan keduanya dikenal dengan gaya kotbah yang berapi-api. Walaupun sangat mirip sehingga kadang sulit membedakan aliran Kharismatik ini dengan aliran Pentakosta yang lahir jauh lebih dahulu daripadanya dan yang menjadi inspirasinya, ada beberapa aspek yang membedakan keduanya seperti kebanyakan Kharismatik menolak keutamaan glossolalia/bahasa roh $^{6}$ yang diberlakukan oleh Pentakosta dan banyak Kharismatik yang seringkali tetap berada di denominasinya sendiri tanpa mendirikan gereja baru, seperti Kharismatik Katolik di Gereja Katolik Roma.

Pentakostalisme dan Kharismatisme tidak lepas dari pendahulunya, yaitu Methodisme. Methodisme merupakan aliran yang diajarkan oleh dua bersaudara John Wesley dean Charles Wesley. John Wesley diberi julukan sebagai "Bapak Pentakolisme" karena banyak ajaran dan gagasan serta pendekatan teologisnya diadopsi oleh Pentakolisme.

Kegerakan Kharismatik ini berkembang sangat cepat dan penyebarannya sangat dirasakan di beberapa negara di dunia seperti Eternal Grace, Newfrontiers, Vineyard Movement, dan Sovereign Grace Ministries. Di Indonesia sendiri, terutama di kota besar seperti Jakarta dan sekitarnya juga dirasakan sangat hebat, seperti Gereja Mawar Sharon (GMS), Charismatic Worship Service (CWS), Gereja Bethany Indonesia (Bethany), Gereja Bethel Indonesia (GBI), Gereja Duta Injil, Gereja Rumah Doa Segala Bangsa (RDSB), Gereja Yesus Kristus Tuhan (Abbalove Ministries), Gereja Tiberias Indonesia (GTI Tiberias), Gereja Bethel Tabernakel (GBT), Gereja Kemenangan Iman Indonesia (GKII), Gereja Jemaat Kristen Indonesia (GJKI). Ada dua gerakan yang memiliki kontribusi sangat besar di Asia

\footnotetext{
${ }^{5}$ Gereja Pentakosta mulai muncul awal abad 20 dari kalangan gereja Protestan. Munculnya gereja Protestan pada awal abad 16 dari penyimpangan dalam gereja Roma Katolik dan keinginan para tokoh Reformasi (Martin Luther, John Calvin, dan sebagainya) untuk kembali pada ajaran Kristen yang sudah ada sejak abad pertama (Back to the Bible).

${ }^{6}$ Bahasa Roh (glossolalia) adalah salah satu karunia Roh Kudus yang memuji Allah di dalam doa dengan bahasa yang baru yang biasanya tidak dapat dipahami oleh orang yang memakainya (Lihat 1 Korintus 12 dan 14).
} 
terhadap pertumbuhan aliran Kharismatik, yakni Assemblies of God $^{7}$ dan Full GospelBusinessmen Fellowship di Amerika. ${ }^{8}$

\section{Musik dalam Gereja Kharismatik}

Dalam sebuah tata ibadah Kristiani, ibadah dan musik tidak dapat dipisahkan, ibarat dua buah sisi mata uang. Ibadah Kristen menurut Hoon adalah pernyataan diri Allah sendiri dalam Yesus Kristus dan tanggapan manusia terhadapNya. Menurut Luther bahwa tidak ada satu pun yang terjadi di dalam ibadah kecuali bahwa Tuhan kita yang pengasih itu sendiri berbicara kepada kita melalui firmanNya yang kudus dan bahwa kita, pada gilirannya, berbicara kepadaNya melalui doa dan nyanyian pujian (James F. White, 2002: 7-8).

Peran musik dalam kehidupan serta ibadah jemaat ada tertulis dalam Alkitab ${ }^{9}$, namun setiap gereja memiliki peran, gaya musik dan porsi musik yang berbeda-beda dalam ibadah mereka. Perbedaan genre ${ }^{10}$ musik dalam musik gereja bukan menjadi masalah mendasar, tetapi lebih kepada muatan musik tersebut, sepanjang musik itu ditujukan untuk memuliakan Tuhan dan mendatangkan berkat bagi jemaat yang mendengarkannya supaya kerohanian mereka bisa bertumbuh.

Menurut John F. Wilson musik itu sendiri tidak mampu menjadikan seseorang menjadi Kristen, juga tidak membuat mereka menyembah. Dalam kenyataannya, bagian pokok keberadaan musik gereja saat ini tidak memiliki perbedaan gaya dalam pelaksanaanya (aransemennya), dalam tatanan fisiknya (instrumennya), dan untuk tujuan-tujuan yang lain. Perbedaaannya terletak pada pengunaannya (John F. Wilsen, 1965: 17).

Menurut James F. White, fungsi utama musik gerejawi adalah untuk menambah dimensi keterlibatan ke dalam ibadah. Alasan mengapa musik membantu ibadah adalah

\footnotetext{
${ }^{7}$ Assemblies of God merupakan salah satu kelompok neo-Pentakostal yang tumbuh ketika kebangkitan kerohanian melanda Amerika di abad ke-19. Dibentuk berdasarkan ide dari pendeta-pendeta Pentakostal untuk menciptakan wadah persekutuan persaudaraan dalam mengkoordinasikan pekerjaan misi di Amerika dan luar Amerika, yang berbasis di Hot Springs, Arkansas. Kemudian Assemblies of God menjadi sebuah organisasi yang terstruktur dan melembaga di bawah sebuah Dewan Umum (General Council) yang diketuai oleh Endorus N. Bell. Walau muncul berbagai reaksi menentang pelembagaan tersebut, tetapi Assemblies of God secara konkret menjadi salah satu denominasi Kharismatik yang terbesar di dunia dengan sebuah tata gereja dan hirarki administratif yang formal. Lih. Wilfred J. Samuel,28.
}

${ }^{8}$ Selanjutnya mengenai sejarah perkembangan Kristen Kharismatik dapat dilihat dalam buku Wilfred J. Samuel, Kristen Kharismatik dan L. Sugiri S., Gerakan Kharismatik Apakah Itu?

\footnotetext{
${ }^{9}$ Musik merupakan syarat mutlak dalam pujian karena umat Kristiani meyakini bahwa Allah bertahta di atas pujian umatNya. (lihat Kitab Mazmur 66:17 dan Kitab Efesus 5:19).

${ }^{10}$ Genre merupakan istilah bahasa Prancis yang berarti jenis atau gaya atau style atau kategori, seperti symphony, himne, march, ballad dan sebagainya.
} 
bahwa musik merupakan medium yang lebih ekspresif dibanding ucapan biasa, musik memungkinkan kita mengekspresikan intensitas perasaan melalui kepelbagian dalam kecepatan, pola titik nada, keras lembut, melodi dan ritme, dan musik dapat, dan sering, menyampaikan intensitas lebih besar dalam perasaan dibanding kalau diekspresikan tanpa disertai musik James (F. White, 1990).

Di awal kitab Kejadian (Kejadian 4:21) telah ditunjukkan bahwa Allah adalah Pencipta musik, sumber inspirasi musik dan menyukai musik. ${ }^{11}$ Pada zaman pemerintahan theokrasi, melalui para nabi, hakim dan imam, juga pada zaman raja-raja, ${ }^{12}$ Allah memberi porsi yang banyak terhadap musik. Hal ini tidak berarti bahwa teologi/doktrin/firman tidak penting, namun betapa banyak, baik, dan sering seharusnya umat Tuhan mengucap syukur atas keselamatan yang telah diterima seperti yang dinasehatkan pemazmur dalam Kitab Mazmur 100:1-4. ${ }^{13}$ Begitu pentingnya musik dalam gereja, sehingga tidak heran Martin Luther King (1483-1546) sebagai Bapak Reformasi Gereja, pernah berkata, "Music is a gift of God, not a gift of men," dan "After theology, we give the greatest honor to music; let it be music, we will make it as sacred as it needs be." Maksud dari ungkapan di atas adalah bahwa musik merupakan pemberian dari Tuhan bukan pemberian manusia dan setelah teologia/doktrin/firman, mari kita beri penghargaan tertinggi kepada musik; biarlah ada musik, dan kita akan menguduskannya sebagaimana seharusnya. Ronald Allen dan Gordon Borror, penulis buku Worship Rediscovering The Missing Jewel (1952) mengatakan: “Allah menganugrahkan musik agar kita dapat menggunakannya dan mengembangkannya untuk mengungkapkan kreativitas kita dalam penyembahan dan ibadah manusia kepada Allah." Dari uraian diatas maka peneliti berkesimpulan bahwa umat Tuhan seharusnya serius terhadap musik, memanfaatkan musik secara positif dan menempatkannya sesuai proporsinya dalam gereja.

\footnotetext{
${ }^{11}$ Segala sesuatu yang berasal dari Allah memiliki sifat baik. Umat Kristiani memiliki pandangan bahwa Allah adalah Allah dari keberagamandan tidak berdiri diatas keberagaman. Oleh sebab itu Allah tidak bisa diukur sesuai selera pribadi, karena hal itu menjadikannya sombong karena membatasi dan merendahkan Allah.

${ }^{12}$ Seperti raja Daud menempatkan musik secara istimewa, dimana ada orang-orang tertentu yang digaji sebagai tenaga penuh untuk memuji Tuhan siang dan malam: ada jabatan dan aturan-aturan yang ditentukan untuk mereka, ditempatkan dibilik-bilik tertentu, dilengkapi dengan pakaian seragam dan alat-alatmusik lengkap (1 Tawarikh 6:31-32 dan 1 Tawarikh 9:33).

${ }^{13}$ Mazmur 100:1-4 "Bersorak-soraklah bagi TUHAN, hai seluruh bumi! Beribadahlah kepada TUHAN dengan sukacita, datanglah ke hadapan-Nya dengan sorak-sorai! Ketahuilah, bahwa TUHAN-lah Allah; Dialah yang menjadikan kita dan punya Dialah kita, umat-Nya dan kawanan domba gembalaan-Nya. Masuklah melalui pintu gerbang-Nya dengan nyanyian syukur, ke dalam pelataran-Nya dengan puji-pujian, bersyukurlah kepadaNya dan pujilah nama-Nya”.
} 
Perlakuan terhadap cara menyanyi jemaat dan musik yang digunakan dalam ibadah terjadi perkembangan baik dari segi fungsi maupun strukturnya. Alkitab menuliskan peran musik dalam kehidupan serta ibadah jemaat, namun setiap gereja memiliki peran, gaya musik dan porsi musik yang berbeda-beda dalam ibadah mereka. Gereja tradisional misalnya dengan mazmur ${ }^{14}$ saja yang kemudian berkembang dengan adanya himne ${ }^{15}$ yang diiringi dengan piano atau organ dan ibadah yang liturgikal, gereja GBKP (Gereja Batak Karo Protestan) dengan musik tradisional karo yang dimainkan melalui program musik keyboard, GKJ (Gereja Kristen Jawa) dengan musik gamelan atau karawitan dalam tata cara ibadahnya.

Musik yang digunakan dalam ibadah Kharismatik merupakan musik dengan gaya yang sangat berbeda dari gereja-gereja tradisional yang himne (hymn). Tata cara ibadah di gereja Kharismatik lebih dikenal dengan Pujian dan Penyembahan (praise and worship) yang ibadahnya memiliki ciri khas lagu pujian yang sifatnya semangat/antusiasme dan dinamis. Lagu penyembahannya pun menyentuh hati dengan aransemen dan genre musik Kristen pop/kontemporer (Christian contemporary music) ${ }^{16}$ yang juga diikuti dengan penyembahan dalam bahasa roh/glossolalia. ${ }^{17}$ Musik dalam ibadah yang dilakukan oleh kalangan gereja-gereja Kharismatik ini sifatnya lebih spontan dan fleksibel, tidak dilakukan dengan struktur yang kaku, penggunaan tempo yang bervariasi, lagunya mudah disenandungkan dan mudah dipahami, beda dengan musik dalam ibadah yang dilakukan oleh kalangan gereja-gereja tradisional yang penyembahannya dilakukan dengan menyanyikan

\footnotetext{
${ }^{14}$ Mazmur adalah doa gereja yang dinyanyikan. Oleh karena itu,mazmur harus mendapat tempat liturgis sendiri di dalam ibadah. (J. L. Ch. Abineno, Unsur-Unsur Liturgia Yang Dipakai Oleh Gereja-Gereja di Indonesia, Jakarta: BPK Gunung Mulia, 2005), 70. Mazmur juga merupakan nama kitab yang ditulis oleh Raja Daud pada Perjanjian Lama.

${ }^{15}$ Himne (hymn)adalah nyanyian berbait dengan syair baru (bukan dari kitab suci). Himne dan liturgi dikembangkan oleh 2 tokoh besar yaitu Ambrosius (333-397) dan Gregorius Agung (590-604), dimana Ambrosius kemudian dianggap sebagai Bapak Himne Katolik karena nyanyian yang diciptakan oleh kedua tokoh ini digunakan sebagai model himne bagi generasi berikutnya dan sangat mempengaruhi perkembangan musik Barat pada zaman-zaman selanjutnya. (Albert Seay, Music in the Medieval World, New Jersey: PrenticeHall,Inc, 1975), 48.
}

${ }^{16}$ Istilah Christian Music Contemporer dianalogikan sebagai jenis musik gereja di luar kaidah-kaidah musik maupun instrumenasi gereja tradisi yang menggunakan musik bergaya himne (hymn) yang diiringi piano, organ dan sebagainya dalam setiap ibadah, sedangkan Christian Music Contemporer identik dengan terminologi musik masa kini dengan perangkat musik combo band komplit (Winardo Saragih, Misi Musik, Yogyakarta: Andi Offset), 76.

${ }^{17}$ Hal ini sering dikaitkan dengan ayat dalam Injil Yohannes 4:24, “Allah itu Roh dan barang siapa menyembah Dia, haruslah menyembahNya dalam roh dan kebenaran”. Dan kehadiran Allah terjadi ketika manusia melakukan Pujian dan Penyembahan. 
lagu-lagu dari buku-buku himne yang sudah lama dan digunakan sebatas aktivitas liturgis ${ }^{18}$ dengan pola ibadah yang teratur. Pola ibadah pujian dan penyembahan di gereja Kharismatik dipimpin oleh seorang pemimpin pujian (worship leader) yang di back up oleh beberapa penyanyi (singers) dengan menggunakan alat musik yang lebih dikenal dengan istilah combo band, yaitu alat musik yang terdiri dari keyboard, gitar, gitar elektrik, gitar bass elektrik dan drum.

Akan tetapi di dalam pelaksanaannya ibadah di gereja karismatik tidak selamanya menggunakan model atau gaya band. Seringkali unsur-unsur gaya zaman klasik digunakan di dalam ibadah terutama pada bagian penyembahan. Teknik-teknik arpeggio atau semacam broken chord acapkali menghiasi performasi musikal di dalam ibadah Kristen. Penggunaan unsur-unsur klasik ini diakui atau tidak kenyataannya mampu menciptakan suasana yang lain, seperti suasana khikmad. Dengan kata lain, diakui atau tidak, unsur-unsur klasik seperti ini mampu mencipatakan suasana ibadah yang mampu membawa jemaat pada hadirat Allah, walaupun tetap berada dalam konteks contemporary music.

\section{Musik Tradisional di Gereja Kharismatik}

Baik langsung maupun tidak langsung kehadiran gerakan Lutherian bagaimanapun merupakan cikal bakal musik-musik bergaya non-katolik setelah berkurangnya pengaruh gereja katolik di negara-negara Eropa di sekitar Abad 14. Setelah melepaskan diri dari otoritas gereja Katolik Roma, Martin Luther melakukan berbagai pembaharuan sistem liturgi, termasuk tradisi nyanyian di dalam gereja. Ia mulai memasukkan unsur-unsur lokal, tradisi lokal Jerman dalam konteks itu, ke dalam sistem peribadahan. Martin Luther dengan sangat baik memasukkan unsur-unsur musik rakyat (Jerman pada saat itu) ke dalam liturgi gereja protestan. Seiring dengan berjalannya waktu gaya-gaya musik di gereja pun mulai berkembang, berubah, beradaptasi dengan kebutuhan sosial. Hal itu merupakan reaksi terhadap dominasi gereja katolik yang menempatkan Bahasa Latin sebagai bahasa 'resmi' liturgi di semua Gereja Katolik Roma. Seluruh nyanyian pada masa itu berbahasa Latin, tidak hanya pada bagian ordinarium ${ }^{19}$, tetapi juga nyanyian-nyanyian yang lain, termasuk doa Bapa Kami yang dinyanyikan.

\footnotetext{
${ }^{18}$ Kata 'liturgi' berasal dari bahasa Yunani leitourgia, yang artinya mempersatukan orang-orang. Secar populer masyarakata awam mengartikan liturgi sebagai upacara gereja, atau tata cara ibadah gereja dan sebagainya (Alexander Schemann, Sacred and Orthodoxy, New York: Herder and Herder, 1965), 28.

${ }^{19}$ Secara bebas istilah 'ordinarium' bisa diartikan 'yang biasa dilakukan' atau tata cara yang bersifat regular. Dalam tradisi gereja katolik, ordinarium meliputi Kyrie (Tuhan Kasihanilah Kami), Gloria (Kemuliaan kepada Allah di tempat yang mahatinggi), Alleluya (Terpujilah Allah), Sanctus (Kudus), dan Agnus Dei (Anak Domba Allah).
} 
Pada perkembangan selanjutnya Gereja Katolik Roma mengadakan rapat besar yang disebut Konsili Vatikan II. Konsili ini menjadi konsili yang sangat penting dalam kaitannya dengan inkulturasi. Di gereja katolik, istilah 'inkulturasi' ini muncul setelah Konsili Vatikan II (tahun 1965) dan belum muncul di dalam Konstitusi Liturgi. Konstitusi tersebut masih memakai istilah 'adaptasi' atau 'penyesuaian'. ${ }^{20}$ Walaupun begitu, di tahun 1984 Komisi Liturgi MAWI (sekarang KWI) ${ }^{21}$ merumuskan suatu pedoman inkulturasi bersifat sunnah, bukan suatu perintah, atau keharusan. Di situ, 'inkulturasi' diartikan "pengungkapan/perayaan Liturgi gereja dalam tatacara dan suasana yang serba selaras dengan citarasa budaya umat yang beribadat." 22 Tujuannya "agar umat yang mengikuti ibadat terpesona oleh lagu, doa, lambang/hiasan, upacara -karena semuanya langsung dapat dimengerti; 'bagus' menurut penilaian yang dipakai dalam hidup kebudayaan sehari-hari.",23

Di tahun 1970, sidang para Uskup memutuskan, "Perlu sekali bahwa Gereja sungguh-sungguh berakar dan bertumbuh di dalam masyarakat Indonesia dan bahwa nampaklah di luar dengan wajah Indonesia yang jelas. Indonesianisasi atau indigenisasi ${ }^{24}$ Gereja merupakan usaha bersama dari tenaga-tenaga pribumi dan misionaris-misionaris dari negeri lain.” (J. Hadiwikarta, 1981:94). Tampak, di tahun 1970 istilah 'inkulturasi' sama sekali belum dikenal. Istilah 'Indonesianisasi' juga tidak jelas. Yang jelas tidak bermaksud menyeragamkan kebudayaan yang ada.

Berdasarkan laporan dalam bentuk dokumen di Pusat Musik Liturgi Yogyakarta, tahun 1926 di Muntilan, Jawa Tengah, seorang bernama Hardjasoebrata pernah untuk pertama kalinya menciptakan lagu ibadah dengan syair berbahasa Latin, namun dengan nada-nada pelog. Tindakan ini bersifat spontanitas. Bapak Hardjasoebrata 'terdorong' melakukan eksperimen tersebut. Ia sungguh-sungguh Jawa dan sungguh-sungguh Katolik. Walaupun belum terdefinisikan dengan baik, tindakan ini dianggap sebagai tindakan inkulturatif.

Namun demikian kini, seiring dengan dikeluarkannya Instruksi tentang Inkulturasi Liturgi Romawi: Instruksi IV untuk Pelaksanaan Konstitusi Liturgi, art. 37-40, yang

\footnotetext{
${ }^{20}$ Sacrosanctum Concilium, Artikel 38-40.

${ }^{21}$ KWI adalah kependekan dari "Konferensi Waligereja Indonesia".

${ }^{22}$ Ekawarta 3/V/1985, Komisi Liturgi MAWI, Yogyakarta 1984.

${ }^{23}$ Lebih jauh mengenai hal ini dapat dilihat pada Penanggalan Liturgi tahunan yang disusun oleh Komisi Liturgi KWI, terbitan Kanisius Yogyakarta.

${ }^{24}$ Dari kata Latin “indigenea” yang berarti “orang pribumi” atau "pemribumian”.
} 
dikeluarkan di Roma tahun 1994, ikhwal inkulturasi semakin jelas. Sacrosanctum Concilium berbicara mengenai pelbagai bentuk dari penyesuaian liturgi, yang disusul dengan dikeluarkannya Magisterium Gereja yang memakai istilah 'inkulturasi' untuk mendefinisikan penjelmaan Injil di dalam kebudayaan pribumi dan sekaligus masuknya kebudayaan dalam hidup Gereja. 'Inkulturasi' berarti “perubahan batin dari nilai-nilai budaya pribumi melalui pengintegrasian nilai tersebut ke dalam agama Kristen serta melalui penanaman agama Kristen di dalam pelbagai kebudayaan." 25 Pengertian ini dipandang lebih masuk akal ketimbang istilah 'penyesuaian' yang isyaratnya hanya menyarankan untuk diadakan perubahan insidental dan lahiriah saja. ${ }^{26}$

Dengan demikian istilah 'inkulturasi' adalah istilah yang lebih tepat untuk menunjuk adanya gerakan ganda bahwa melalui inkulturasi Gereja melahirkan Injil di dalam berbagai kebudayaan, dan sekaligus mengantar bangsa-bangsa dengan kebudayaannya ke dalam himpunan Gereja. Di satu pihak, Injil "bagaikan dari dalam menyuburkan harta semarak jiwa serta bakat-pembawaan setiap bangsa..., meneguhkannya, melengkapinya, dan membaharuinya di dalam Kristus.” Di lain pihak, Gereja mengangkat nilai-nilai ini, sejauh dapat diperdamaikan dengan Injil, untuk "menyebarluaskan dan menguraikan pewartaan Kristus kepada semua bangsa, untuk menggali dan makin menyelaminya, serta untuk mengungkapkannya secara lebih baik dalam perayaan liturgi dan dalam kehidupan jemaat beriman yang beranekaragam." Dengan demikian gerakan ganda dalam karya inkulturasi mengungkapkan salah satu dari unsur misteri inkarnasi. ${ }^{27}$

Inkulturasi Liturgi Romawi memperhatikan situasi dan kondisi negara-negara yang tidak memiliki tradisi Kristiani atau tempat-tempat misi para misionaris. Persoalannya, Gereja bila berkontak dengan kebudayaan lain harus menyambut dengan baik tradisi suatu bangsa yang dapat diperdamaikan dengan Injil, untuk memberi kepada mereka kekayaan Kristus; sebaliknya, "Gereja akan diperkaya dengan berbagai bentuk kebijaksanaan dari bangsa-bangsa di dunia." 28 Inilah inkulturasi yang dimaksud dan mendapat tempat di dalam

\footnotetext{
${ }^{25}$ Johanes Paulus II, Ensiklika Redemptoris Misio, 7 Desember 1990, no.52. Dalam AAS 83 (1991) 300, seperti diterjemahkan dan dikutip Karl-Edmund Prier, SJ. Pernyaan ini pula yang menjadi inspirasi bagi Konstitusi Liturgi yang dikeluarkan tahun 1994.

${ }^{26} \mathrm{Hal}$ ini lebih ditegaskan lagi di dalam Sinode Uskup berupa Laporan Penutupan Exeunte coetu secundo, terjemahan Karl-Edmund Prier, SJ., 7 Desember 1985. Oktober 1979.

${ }^{27}$ Johanes Paulus II, Surat Apostolis Catechesi Tradendae, terjemahan Karl-Edmund Prier, SJ., 16

${ }^{28}$ Yohanes Paulus II, Sambutan kepada Sidang Pleno, Dewan Kepausan untuk Kebudayaan, terjemahan Karl-Edmund Prier, SJ., 17 Januari 1985.
} 
ibadah dan mencakup juga strategi pastoral. Jika diperhatikan, konsep inkulturasi 'gaya' Katolik ini terjadi sejauh "dapat diperdamaikan dengan Injil," dan terjadi karena keinginan dua arah.

Dengan demikian, inkulturasi dalam konteks Gereja Katolik adalah transformasi nilainilai kebudayaan otentik secara mendalam melalui proses integrasi mereka ke dalam kekristenan, dan meresapnya kekristenan ke dalam kebudayaan umat manusia. Melalui inkulturasi, Gereja menjelmakan Injil dalam kebudayaan-kebudayaan yang berbeda-beda dan serentak membawa masuk para bangsa bersama dengan kebudayaan-kebudayaan mereka ke dalam persekutuan Gereja sendiri.

Itulah yang mendasari bentuk musik inkulturasi. Bisa dikatakan: musik Gregorian dianggap 'cahaya Injil', sedangkan musik Jawa adalah 'kebudayaan para bangsa'. Antara musik Gregorian dan Jawa terjadi kontak. Musik Gregorian 'memberi kekayaan Kristus' kepada musik Jawa, namun di sisi lain, musik Jawa yang bersandar pada dimensi 'batin' untuk terus mencari dan memelihara ketenteraman hati (introvert), memperkaya musik Gregorian lewat lebijaksanaannya itu. Dengan terbukanya 'pintu' inkulturasi itu, Gereja tidak menganggap satu corak kesenian pun sebagai khas bagi dirinya. Yang terjadi justru sebaliknya, pintu inkulturasi itu menghasilkan kebudayaan baru. Itulah sebabnya, di dalam wacana musik liturgi Gereja Katolik bahwa istilah 'Jawa-Gregorian' sesungguhnya kurang tepat. Yang tepat adalah 'musik inkulturasi Jawa' yang artinya, musik liturgi Katolik Roma bertemu dan bersinergi dengan musik Jawa, karena pada kenyataanya musik Gregorianlah yang 'mengetuk pintu' musik Jawa sebagai bagian dari upaya misi di dunia.

Inilah transformasi, di satu pihak melepaskan, tetapi di sisi lain memberikan kekhasannya yang otentik. Kekhasan kedua belah pihak itu terintegrasi untuk saling membangun, mengembangkan, dan menghidupkan nilai-nilai yang mengacu pada perdamaian, kesejukan, dan 'terang Kristus'. Inilah transformasi budaya yang menghasilkan 'ciptaan baru' yang dilandasi iman, harapan, dan kasih. Pun secara sosiologis, 'gerakan' inkulturasi menunjukkan, gereja ini terus melakukan perubahan ke arah yang lebih baik.

Gereja Kharismatik justru bertindak sebaliknya. Pengaruh gaya gospel dari Amerika dan penitikberatan pada karunia Roh menjadi sangat dominan. Musik di dalam gereja karismatik banyak dipengaruhi oleh budaya Barat, terutama Amerika. Musik-musik dengan bentuk band menjadi sangat lekat yang nota bene berhubungan langsung dengan perkembangan teknologi. Hal ini sangat terkait dengan gerakan penginjilan yang sangat gencar, dimulai sejak sebelum pecah Perang Dunia. Sasarannya adalah kaum muda yang pada 
massa itu sangat akrab dengan kehidupan hedonis. Fungsi musik dalam konteks ini lantas ditransformasikan dengan kebenaran Alkitab.

Berdasarkan perspektif gereja karismatik, musik adalah adalah sarana efektif dalam 'membawa' jemaat menghadap, berkomunikasi, dan berinteraksi dengan Tuhan Allah; menyatukan jemaat dalam kebersamaan di dalam ibadahnya. Hal ini juga tertulis di dalam Alkitab, seperti yang tertulis di dalam Mazmur 150:3-6 yang berbunyi, “(3) Pujilah Dia dengan tiupan sangkakala, pujilah Dia dengan gambus dan kecapi! (4) Pujilah Dia dengan rebana dan tari-tarian, Pujilah Dia dengan permainan kecapi dan seruling! (5) Pujilah Dia dengan ceracap yang berdenting, Pujilah Dia dengan ceracap yang berdentang! (6) Biarlah segala yang bernapas memuji Tuhan! Haleluya!”

Di awal Kitab Kejadian (Kej. 4: 21) telah ditunjukkan bahwa Allah adalah pencipta musik, sumber inspirasi musik dan menyukai musik, "Nama adiknya ialah Yubal: dialah yang menjadi bapa setiap orang yang memainkan kecapi dan seruling." Nats ini setidaknya menunjukkan bahwa sejak awal hubungan manusia dengan Tuhan sudah ditandai dengan hadirnya aspek-aspek musikal.

Pada masa pemerintahan teokrasi, melalui para nabi, hakim, dan imam, juga pada zaman raja-raja, Allah memberi aresiasi yang cukup baik terhadap eksistensi musik. Raja Daud misalnya, menempatkan musik secara istimewa, menggaji para tenaga penuh waktu untuk memuji Tuhan siang dan malam; ada jabatan dan aturan-aturan yang ditentukan bagi mereka, ditempatkan di bilik-bilik tertentu, dilengkapi dengan pakaian seragam dan alat-alat musik yang lengkap (1Tawarikh 6:31-32 dan 1 Tawarikh 9:33).

Pemahaman akan tradisi seperti ini dan pengaruh metode penginjilan di dalam tradisi kekristenan Barat yang akhirnya menyulitkan adanya pemahaman akan kemungkinan pengaruh musik di luar tradisi gereja di dalam sistem liturgi. Musik tradisional dianggap di luar tradisi Kristen, dan diasumsikan tidak mungkin membawa jemaat kepada iman akan Kristus. Akhirnya musik-musik tradisi agak 'dicurigai' berpeluang membawa jemaat pada kekafiran. Pemahaman semacam ini terus berkembang, bahkan muncul di beberapa kelompok gereja di Indonesia.

Salah satu perkembangan yang menarik dan signifikan adalah mulai hadirnya musik bergaya pop ke dalam gereja-gereja karismatik sejak awal abad 21. Gereja kristen mulai melihat kebutuhan-kebutuhan yang berkembang di masyarakat di masyarakat, dan mulai menggunakannya bukan semata-mata sebagai sarana ibadah, tetapi juga sebagai sarana penginjilan. Adaptasi ini dipandang efektif sebab lewat musik-musik yang berkembang di masyarakat, mereka yang sebelumnya belum mengenal Firman Allah, mulai tertarik dan 
akhirnya masuk ke dalam pertobatan yang kudus. Maka dimulailah abad gerakan karismatik yang memasukkan gaya musik pop dengan menggunakan insturmen band.

Dari kronologi singkat ini terlihat bahwa terjadi pergeseran budaya, kalau tidak boleh dibilang pembalikan budaya. Kalau dulu gereja katolik bersikukuh mempertahankan tradisi kekatolikan dengan menampilkan musik-musik konvensional berbahasa Latin, kini melalui Konsili Vatikan II (dalam dokumen Musicam Sacram) Gereja Katolik justru memberi perhatian khusus pada upaya inkulturasi di dalam sistem liturginya. Sebaliknya gereja karismatik menjaga tradisi westernnya agar sekurang-kurangnya terhindar dari unsur-unsur tradisional yang berkembang di masyarakat, walau memang tidak semua gereja karismatik tidak menjaga tradisinya seketat itu, seperti yang dilakukan Gereja Injili Sepenuh Indonesia (GISI).

\section{Kesimpulan}

Gereja, pada dasarnya berkembang dan pada gilirannya beradaptasi dengan lingkungan sosial dan kultural tempat gereja itu berada. Di era yang dipenuhi jalur-jalur komunikasi yang padat, cepat, dan singkat ini gereja tidak mungkin lagi bersikap ekslusif. Gereja karismatik sudah seyogianya membuka diri bagi unsur-unsur kultural dari luar dan masuknya unsur-unsur tradisi lokal bagaimanapun merupakan keniscayaan.'Kecurigaan' terhadap hal-hal yang dianggap bukan tradisi gereja sudah selayaknya tidak lagi mendapat tempatdi masyarakat plural. Gereja harus menampilkan sosok yang fleksibel dan 'ramah' karena bagaimanapun ia berada di dalam kebudayaan Indonesia, yang jika diamati secara jernih, memiliki kesesuaian dengan ajaran cinta kasih Kristus yang terlihat di dalam pelbagai keutamaan, seperti kebaikan, keugaharian, keadilan, kejujuran, dan sikap menghargai sesama manusia.

\section{Daftar Pustaka}

Albineno, Ch. J.L. Gerakan Pentakosta dan Gerakan Pentakosta Baru (Gerakan Kharismatik. Jakarta: BPK Gunung Mulia, 1976.

Apel, Willi. Harvard Dictionary of Music. Massachussets: Harvard University Press, 1964.

Berglund, Robert D., A Philosophy of Churc Music. USA: Library of Congress, 1985.

Ekawarta 3/V/1985, Komisi Liturgi MAWI, Yogyakarta 1984.

Ewen, David. The Home of Musical Knowledge. New Jersey, Prentica Hall, 1986. 
Florovski, George, The Modern of Classical Music. Bloomington: Indiana University Press, 2009.

Karl Rahner, Karl. Encyclopedia of Theology: A Concise Sacramentum Mundi. USA: Continuum International Publishing Inc., 1975.

Hadiwikarta, j. Pr., Himpunan Keputusan MAWI 1924-1980. Jakarta: Obor, 1981.

Hardjana, Suka. Corat-Coret Musik Kontemporer Dulu dan Kini. Jakarta: Ford Foundation dan MSPI, 2003.

Handojo, Djohan E The Fire of Praise and Worship .Yogyakarta: Andi Ofset, 2007.

Hauser, Arnold. The Sociology of Art. Chicago: University of Chicago Press, 1979.

Johanes Paulus II, Surat Apostolis Catechesi Tradendae, terjemahan Karl-Edmund Prier, SJ., 16 Oktober 1979.

Johanes Paulus II, Ensiklika Redemptoris Misio, 7 Desember 1990, no.52. Dalam AAS 83 300, seperti diterjemahkan dan dikutip Karl-Edmund Prier, SJ., 1991.

Johansson, Calvin M. Music and Ministry: A Biblical Counterpoint. USA: Hendrickson Publisher, 1998.

Kamien, Roger. Music: An Appreciation. New York: McGrwa Hill Inc., 1994

Kennedy, Michael. The Oxford Concise Dictionary of Music. Oxford: Oxford University Press, 2007).

McNeill, Rhoderick J. Sejarah Musik2 (Jakarta: Gunung Mulia, 2003.

Meyendorff, John. The Byzantine Legacy in the Orthodoox Church. SA: St. Vladimir's Seminary Press, 1982

Rahner, Karl. Encyclopedia of Theology: A Concise Sacramentum Mundi (USA: Continuum International Publishing Inc., 1975.

Ratner, Leonard G. Classic Music: Expression, Form, and Style .USA: Schirmer Books A Division of Macmillan Publishing Co.. Inc, 1980,

Riemer G., Cermin Injil. Jakarta: Yayasan Komunikasi Bina Kasih, 1995.

Ross, Ralph. Symbols and Civilazation: Science, Morals, Religion, Art. New York and Burlicame: A Harbinger Book Harcourt, Brace and World, Inc., 1997.

Samuel, Wilfred J. Kristen Kharismatik. Jakarta: BPK Gunung Mulia, 2006.

Saragih, Winardo. Misi Musik. Yogyakarta: Andi Offset, 2007. 
Sasongko, Hari. "Jazz Music and Its Concise History in Indonesia." Jurnal Abdiel, Vol. 4. No.2. Oktober 2014, STT Abdiel, Semarang Jawa Tengah.

Schemann, Alexander. Sacred and Orthodoxy. New York: Herder and Herder, 1965.

Sevy, Albert. Music in the Medieval World. New Jersey: Prentice-Hall,Inc, 1975.

Sugiri S., L. Gerakan Kharismatik Apakah Itu? Jakarta: BPK Gunung Mulia, 2006.

White, James F. Pengantar Ibadah Kristen. Jakarta: Gunung Mulia, 2002.

Wolff, Janet. The Social Production of Art. New York: New York University Press, 1993. 
